\title{
Cardiac surgery in the setting of trisomy 13
}

\author{
Judith Goodship
}

Division of Human Genetics, University of Newcastle-upon-Tyne, Newcastle-upon-Tyne, UK

\section{$\mathrm{T}$} HE CASE REPORT DESCRIBING CARDIAC SURGERY in a baby with trisomy $13^{1}$ opens debate about the role of surgery in children with poor life-expectancy. The baby they describe had multiple congenital abnormalities and, at 3 months of age, had cardiac failure that failed to respond to conservative treatment. Following surgical repair, the parents were able to look after her at home for the remaining 7 months of her life. During the post-operative period, chromosome analysis was undertaken, and revealed the presence of trisomy 13. Chromosome analysis should be offered in the neonatal period to the parents of all children with multiple abnormalities, and it is not clear why it was delayed in this case, nor is it clear if the decision to operate would have been different if the diagnosis had been known. Surgery in this child, nonetheless, meant that she was able to be at home rather than being intensively managed in a hospital setting.

Early series had described a poor prognosis in trisomy 13 . Baty and colleagues, ${ }^{2}$ however, have suggested that the long-term survival might be better. In their survey, 12 out of 32 children with trisomy 13 were alive at 12 months of age, and 4 remained alive at 5 years of age. Ascertainment of these cases was biased, as they were drawn from families who were members of the support organisation for trisomy 18 , trisomy 13 , and related disorders. Seven of the children had undergone surgery in the neonatal period, but none had required cardiac surgery. Because of this report, colleagues in the Northern Region of the United Kingdom carried out a population-based study of the natural history of trisomy $13 .{ }^{3}$ Of 16 consecutive live births, the median survival with trisomy 13 was 4 days, and the longest survival 90 days. Cardiac defects were not the cause of death in any of these cases, and no patients developed cardiac failure. Survival beyond 3 months in trisomy 13 is the exception rather than the rule, and cardiac surgery would rarely affect outcome.

\section{References}

1. Stromme P, Thaulow E, Geiran O. Cardiac surgery in a girl with trisomy 13. Cardiol Young 2000;10: 638

2. Baty B J, Blackburn B L, Carey JC. Natural History of Trisomy 18 and Trisomy 13: I.Growth, Physical Assessment, Medical Histories, Survival, and Recurrence Rusk. American Journal of Medical Genetics 1994; 49: 175-188

3. Wyllie J P, Wright M J, Burn J, Hunter S. Natural history of Trisomy 13. Archives of Disease in Childhood 1994; 71 : $343-345$. 